\title{
Orçamento e Contabilidade Nacional *
}

\author{
MAX Frank \\ Tradução de Maria de Lourdes L. Modiano
}

$A$ "Revista do Serviço Público" sempre tem procurado pôr os seus leitores a par da revisão geral de concepção e de métodos por que vem passando a Contabilidade Pública, particularmente no setor orçamentário. Divulgou, por isto, em número anterior - o de novembro de 1954 - parte do Relatório da Comissão Hoover, no qual se propõe, entre outras medidas, uma reforma radical dos processos adotados, pela Administração Federal Norte-americana, na elaboração orçamentária e na contabilidade das despesas públicas. Reconheceu, assim, aquela Comissão, a necessidade de se reformular êsse problema de administração financeira, não obstante a fecunda experiência já acumulada desde 1921, - ano do Budget and Accounting Act - pelo Govêrno Federal dos E.U.A. Daí também a conclusão a que chegou de se controlarem a vários dos seus aspectos - o econômico, o financeiro, o administrativo e o contábil - quaisquer operações financeiras do Govêrno, pois uma espécie de contrôle não supre necessàriamente a outra.

O balançg realizado por MAX Frank, que ora divulgamos, foi publicado em primeira mão pela Reuve Internationale des Sciences Administratives (iniciativa do Instituto INTERNACIONAL DAS CiênCIAs AdMINISTRATIVAS), e diz respeito a questóes ou problemas que se discutiram durante a Jornada de Estudos, realizada pelo Instituto BeLGa DE FinançAs. Permite, assim, que a "Revista do Serviço Público" forneça a seus leitores outra oportunidade para ampliar informações e conhecimentos sôbre o estado atual da discussão do assunto.

Convém assinalar, dentre os pontos de vista analisados nessa ocasião, o que maior interêsse despertou: a conveniência, hoje em dia quase por todos admitida, de se integrar a Contabilidade Pública na Contabilidade Nacional, o que justificou a criação de uma Comissão de Estudos para a integração da Contabilidade Pública na Contabilidade Nacional, especialmente incumbida de examinar e resumir os trabalhos da Jornada de Estudos e de apresentar, também, recomendações que visem à concretização da reforma projetada.

$A$ recente remodelação introduzida na apresentação da despesa pública do Orçamento Federal mostra que o problema, de certo modo, já vem despertando o interêsse dos responsáveis pela Administração financeira de nosso país. E porque ainda nos encontremos no limiar de qualquer solução de maior 
alcance e profundidade no assunto, haverá sempre utilidade para o nosso público, mesmo não especializado, em conhecer como a questão vem sendo encarada em outros centros de cultura.

(Nota da Redação)

O Instituto Belga de Finança Pública realizou, no dia 6 de dezembro de 1952, uma Jornada de Estudos, dedicada ao tema "Orçamento e Contabilidade Nacional."

Essa Jornada, presidida pelo Sr. MAX-LÉo GÉrard, Presidente de honra do Instituto BELGA DE FinANÇA PÚBliCA, foi prestigiada pela presença dos Srs. J. VAN HouTte, primeiro ministro e presidente do INSTITUTO BELGA DE Finança Pública, H. Janssen, ministro das Finanças e H. Matton, Primeiro Presidente honorário do Tribunal de Contas.

Depois de uma alocução pronunciada pelo $\mathrm{Sr}$. J. VAN HouTtE, primeiro ministro, foram tratados os seguintes assuntos:

- Reforma da apresentação do orçamento do Estado, pelo $\mathrm{Sr}$. M. Frank, Inspetor da Fazenda.

- Contabilidade patrimcnial do Estado, pelo Sr. M. G. ILEGEMS, Inspetor-Geral da Fazenda.

- Situação patrimonial do Congo Belga a 31 de dezembro de 1949, pelo Sr. VerRIEST, Inspetor Real das Colônias.

- Problemas de terminologia e de classificação, pelo Sr. A. Buttgenbach, Professor da Universidade de Liège.

- Reforma da apresentação do orçamento dos órgãos de interêsse público, autônomos, pelo $\mathrm{Sr}$. A. Magain, Chefe de Gabinete do Primeiro Ministro.

- Previsão da conta da Tesouraria, pelo Sr. M. E. Chatel, Chefe de Escritório da Administração da Tesouraria.

- Contabilidade nacional, instrumento de análise estatística ou de política econômica? pelo Sr. V. de RIDDER, Doutor em Ciências Econômicas.

Em seu discurso introdutório, frisou o $\mathrm{Sr}$. VAN HouTTE o interêsse, tanto científico como prático, dos estudos relativos a orçamento e contabilidade nacional.

Do ponto de vista científico, é incontestável êsse interêsse. Graças à contabilidade nacional, as ciências econômicas e financeiras dispõem de dados quantitativos sintéticos, que refletem as atividades dos diferentes setores da eccnomia, até mesmo de tôda a economia.

Essas cifras globais, chamadas macro-econômicas, abrem novos horizontes à economia política, uma época em que esta atravessa importante crise.

No que tange às finanças públicas, especialmente, a ccntabilidade nacional as enriquece com novas e férteis concepções. E assim que, considerado 
outrora como simples ato de previsão e autorização das receitas e despesas do Estado, e estabelecido, de certo modo, à margem da atividade do setor privado, passa o orçamiento, graças às contas da nação, a ser orgânicamente ligedo à economia geral do país.

Do ponto de vista prático, êsses estudos apresentam não menor interêsse. Com efeito, os dados relativos à renda nacional e à contabilidade nacional ocupam lugar cada vez mais importante nas discussões econômicas, financeiras e sociais, no plano interior e, ainda mais, e, ainda mais, no plano exterior - notadamente no seio da O.N.U., da Organização Européia de Cooperação Econômica, do Conselho do Tratado do Atlântico Norte e do Fundo Monetário Internacional.

A comunicação do Sr. Frank, Inspetor da Fazenda, visava à "adaptação da apresentação do orçamento do Estado, no sentido de permitir sua integração na Contabilidade nacional".

O plano do orçamento do Estado, baseado na contabilidade nacional, proposto pelo $\mathrm{Sr}$. FraNk, compreende três documentos essenciais:

- Orçamento dos serviços do Estado, relativos às operações dcs serviços governamientais e de caráter social, do Estado (vide Quadro 1);

- Orçamento das emprêsas do Estado e demais emprêsas públicas nacionais;

- Previsão da conta da Tesouraria, mostrando como será o orçamento financiado.

Com os dois últimos dêsses três dccumentos deviam ser comentados mais especialmente pelos Srs. Magain e Chatel, a exposição do Sr. Frank girou essencialmente em tôrno do orçamento dos serviços do Estado.

No Quadro 1, encontra-se o plano do orçamento dos serviços do Estado, baseado na contabilidade nacional.

Examinando-se mais detidamente êsse plano, verifica-se que o mesmo comporta, na realidade, dois documentos - um orçamento das operaçóes correntes e outro das operações de capital.

O plano em questão apresenta o conjunto das operações do Estado numa forma que põe claramente em evidência:

- a ação do Govêrno central como gerente dos serviços públicos administrativos e como gerente das emprêsas públicas;

- a parcela dos recursos públicos destinada, respectivamente, a despesas de consumo e despesas de transferência em favor de em-

(1) O texto dêsse relatório foi publicado na íntegra no $\mathrm{n}^{\circ} 55$, de julho de 1953 , de Statistį̧ues et Etudes Financières, Paris. 
prêsas ou particulares, e a despesas de investimento no setor público;

- finalmente, a incidência das necessidades financeiras do Estado sôbre o mercado de capitais.

O que distingue essencialmente os orçamentos belgas atuais de um crçamento baseado na contabilidade nacional é que êste último reagrupa e apresenta o conjunto das receitas e despesas públicas segundo critérios econômicos, ao passo que aquêles publicam êsses mesmos dados numa ordem e sç denominações que atendem por demais a preocupações puramente administrativas.

\section{ORÇAMENTO DOS SERVIÇOS DO ESTADO}

\section{Classificação segundo a natureza das receitas e despesas}

\section{A. ORÇAMENTO DAS OPERAÇÕES CORRENTES}

\section{Despesas de consumo}

1. Salários e emolumentos (inclusive pensões de velhice).

2. Contribuições patronais do Estado para a Seguridade Social.

3. Bens e serviços adquiridos de terceiros.

4. Amortização de bens de capital.

II. Juros da divida pública

III. Despesas de transferência de rendas

1. A particulares (pensões de guerra, pagamentos da Seguridade Social, subvenções e auxílios diversos.

2. A emprêsa (subvenções econômicas).

3. A governos subordinados.

4. A países estrangeiros.

IV. Despesas de transferência de capitais.

1. A particulares (danos de guerra, prêmios para construções, etc.).
1. Receitas de exploração, ordinárias

1. Receitas do patrimônio público.

2. Foros e laudêmios rendimentos fixos diversos.

II. Receitas da Seguridade Social

1. Contribuição dos empregados.

2. Contribuição dos empregadores (inclusive o Estado).

III. Receitas de transferência de rendas

1. Impostos diretos.

2. Impostos indiretos.

IV. Receitas de transferência de capitais

1. De particulares (inclusive direitos de sucessão).

2. De emprêsas.

V. Receitas financeiras (decorrentes da participação do Estado em emprêsas públicas ou privadas).

1. Juros.

2. Lucros. 
VI. Donativos do exterior (para fins de consumo).

VII. Deficit do orçamento das operações correntes.

B. ORÇAMENTO DAS OPERAÇõES DE CAPITAL

1. Deficit do orçamento das operações correntes

11. Aquisição de bens de capital

1. Novos investimentos.

2. Obras de conservação geral e reformas.

III. Modificações de capitais

1. Adiantamentos ou empréstimos.

a) a emprêsas públicas

b) a governos subordinados e no exterior.

2. Participações em emprêsas públicas.
IV. Amortização da dívida pública

1. Superavit do orçamento das operações correntes

II. Reserva de amortização

III. Revenda de bens de capital

IV. Modificações de capitais

1. Pagamento ao Estado, de adiantamentos ou empréstimos:

a) por emprêsas públicas;

b) por governos subordinados e no exterior.

2. Participação em emprêsas públicas.

IV. Amortização da dívida pública

b) por governos subordinados e no exterior.

2. Cessão, pelo Estado, de suas participações em emprêsas públicas.

V. Excedentes das despesas de capital sôbre as receitas de capital.

Sr. Frank expôs minuciosamente as divergências existentes entre a estrutura do orçamento do Estado baseado na contabilidade nacional e a dos docur_entos orçamentários belgas atuais. Êstes últimos não se prestam bem à escrituração das receitas e despesas do govêrno central nas contas do setor Estado, da contabilidade nacional.

As autoridades holandesas que, após a segunda guerra mundial, enfrentaran! idênticas dificuldades, encontraram solução hábil e eficaz para êsse problema de classificação orçamentária.

Os documentos orçamentários holandeses incluem, atualmente, uma tríplice classificação das receitas e despesas do Estado. nadcr;

- subdivisão, em artigos, das receitas, por departamento orde-

- classificação funcional das despesas;

- classificação segundo a natureza das receitas e despesas.

A subdivisão, em artigos, das receitas e despesas, por departamento ordenador, aplicando aos mesmos o princípio da especialidade orçamentária, não exige explicação especial. E' a que existe na Bélgica. 
A classificação funcional subdivide as despesas do Estado em função do respectivo destino, isto é, segundo as diferentes tarefas assumidas pelo Estado; defesa nacional, negócios exteriores, justiça, educação, corrunicações, etc.... Cor:preende dezesseis rubricas principais, cada uma delas subdividida, segundo as necessidades, em duas, três, quatro ou mais sub-rubricas.

A classificação segundo a natureza das receitas e despesas subdivide as mesmas segundo os fluxos econômicos a que pertencem: despesas de consumo, despesas de transferência, de investimentos, receitas de exploração, receitas de transferências, etc. Abrange nove rubricas de despesas e sete rubricas principais de receitas. Cada uma dessas rubricas principais abrange certo número de rubricas divisionárias, as quais, por sua vez, podem ser distribuídas em sub-rubricas.

Pormenor importante: as duas novas classificações figuram apenas no "desdobramrento" do orçamento. Em compensação, a subdivisão tradicional, em artigos, das receitas e despesas figura apenas nos quadros das leis orçamentárias.

Graças às duas novas classificações de receitas e despesas públicas, introduzidas nos orçamentos da Holanda, a transposição das operações orçamentárias daquele país para a contabilidade nacional ficou reduzida a simples problema de mecanografia.

O conferencista tratou, igualmente, da incidência da reforma proposta, no equilíbrio do orçamento ordinário. Eis as conclusões a que chegou:

1. O equilíbrio do orçamento das cperações correntes, mesmo na estrutura de um sistema baseado na contabilidade nacional, não é noção puramente contábil. Sofre a influência das preocupações políticas e financeiras que não podem ser esquecidas, principalmente no terreno da Defesa Nacional.

2. Os documentos orçamentários, em sua forma atual de apresentação, tendem, de certo modo, a superestimar os encargos correntes ou ordinários e, por conseguinte, a apresentar o resultado do orçamento crdinário sob prisma menos favorável que a realidade. Isso é atribuído à inclusão, no orçamento ordinário, das despesas de amortização da dívida pública, no lugar onde deveriam figurar os ônus relativos ao desgaste econômico do bens do Estado.

Resta, finalmente, aludir às medidas concretas, preconizadas pelo $\mathrm{Sr}$. FrANK, para que as receitas e despesas do Estado possam fàcilmente integrarse na contabilidade nacional. Essas medidas, contra tôdas as expectativas, não teriam caráter muito radical e, principalmente, pouco afetariam as praxes parlamentares. De fato, convém não esquecer que o esquema do orçamento baseado na contabilidade nacional, reproduzido no Quadro anexo, é, apenas, um plano geral. Nada impede, pois, que os vários documentos orçamentários cortinuem, como dantes, a levar em conta as atribuições ministeriais e que sejam apresentados ao Parlamento tantos orçamentos quantos ministros responsáveis existam. 
As subdivisões atuais das receitas e despesas, em artigos, tampouco serian: afetadas pela reforma, já que bastando alguns retoques nas propostas, bem como a subdivisão dos artigos que encerraram operações de natureza muito heterogênea. Conclui-se, com efeito, do exemplo holandês, que as duas classificações orçamentárias necessárias à contabilidade nacional (classificação segundo a natureza das receitas e despesas e classificação funcional das mesmas) podem figurar sòmente nos "desdobramentos" isto é, - serão feitas a margem dos quadros da lei orçamentária pròpriamente dita.

O que importa é, de um lado, que a subdivisão dos créditos orçamentários permita sejam feitas as classificações acima referidas e, de outro, que se incluem na Exposição geral do orçamento, quadros recapitulativos, que sintetizem o conjunto das operações orçarrentárias, segundo o plano de orçamento baseado na contabilidade nacional.

Apenas o crçamento das receitas e despesas extraordinárias e o das receitas e despesas à ordem teriam de sofrer modificações importantes de estrutura,

Isto pôsto, passaremos a enumerar sucintamente as medidas a serem tomades com o fim de facilitar a integração das receitas e despesas públicas na contabilidade nacional.

1. Conviria, primeiramente, ajustar uma classificação segundo a natureza das receitas e despesas e uma classificação funcional das mesmas, segundo um plano geral, inspirado nos princípios da contabilidade nacional.

2. Em segundo lugar, seria mister rever, um por um, cêrca de dois mil itens dos orçamentos, a fim de levar a efeito, de um lado, uma discriminação mais clara entre as operações correntes e as operações de capital e, de outru lado, introduzir, no título e no ccnteúdo dos créditos, os retoques exigidos pelas duas novas classificações das receitas e despesas do Estado.

3. A terceira inovação a ser introđuzida refere-se à substituição do ítem "Amortização da dívida pública" pelo de "Amortização dos bens do Estado", no orçarrento ordinário. Êsse ponto está ligado ao problema da introđução de uma contabilidade patrimonial do Estadc, discutida durante a Jornada de Estudos de 6 de dezembro de 1952, pelo Sr. ILEGEMS, Inspetor Gera! da Fazenda.

4. Seria necessário, ainda, publicar o orçamento dos serviços do Estado de caráter industrial, comercial ou financeiro, como, por exemplo, os Correios, a "Régie du Moniteur", a Linha de Vapores Ostende - Dover, como anexos do orçamento de departamento ministerial a que estão êsses serviços subordinados.

5. Ccnviria, finalmente, reformar inteiramente a apresentação do orçamento de receitas e despesas extraordinárias, bem como o das receitas e despesas à ordem. Esses dois orçamentos, tão importantes, não se prestam, em sua forma atual, à escrituração, na contabilidade nacional, das operações que abrangem, nem a um contrôle político apropriado por parte do Parlamento. 
A comunicação do Sr. ILEGEMS, Inspetor Geral da Fazenda, referia-se à "Corttabilidade patrimonial do Estado". $\mathrm{Na}$ realidade, defendia a adoção cêsse tipo de contabilidade na Bélgica.

Segundo o Sr. IlEgEmS, o Estado deve ser considerado não como consumidor, mas como produtor, atuando sem finalidades de lucro. Considerando que os bens e serviços produzidos pelo Estado são, na sua maioria, concedidos e prestađos gratuitamente, seu valor deve ser fixado em função do custo de produção. Êsse custo de produção compreende os salários e emclun.entos dos agentes do Estado, os bens e serviços adquiridos de terceiros, o ônus de amortização dos bens de capital e, finalmente, os juros das dívidas contraídas para a aquisição dêsses bens de capital.

A determinação dêstes dois últimos elementos do custo de produção exige conhecimento claro do valor e da composição dos bens capitais do Estado. Essas informações serão fornecidas pela contabilidade patrimonial.

O conferencista lembrou mais uma razão para justificar a instituição de uma contabilidade patrirronial do Estado. E' que graças a essa contabilidade, se torna possível determinar, de maneira objetiva, se as obras de conservação e renovação, levadas a efeito pelo Govêrno, são suficientes para manter em boas condições o patrimônio do Estado.

A reforma proposta reveste-se de importância ainda maior, quando se considera que os bens do Estado constituem a parcela principal do balanço do Estado. O saldo entre as parcelas de débito e crédito dêsse balanço corresponde ao valor do patrimônio do Estado. Trata-se de dado muito importante, pois sempre se considerou que o montante da dívida pública não pcde ultrapassar o valor dêsse patrimônio.

$\mathrm{E}$ o Sr. Ilegems passa a citar, nesse particular, o seguinte trecho de um relatório datado de 1.900 , da Seção Central da Câmara dos Representantes, relativo a um projeto de lei sôbre a amortização da dívida pública:

"A existência de uma dívida justifica-se na proporção em que o ativo constituído pelos fundos de empréstimo representa, enr. qualquer época (em capital e rendimento) o contravalor certo do passivo (em principal e ônus). Essa fórmula implica a obrigação, por um lado, de calcular a contrapartida da dívida, não segundo o preço que custou, mas segundo seu valor atual e o rendimento prcduzido, tanto para o Tesouro como para a atividade econômica do país; e, por outro lado, a obrigação de levar em conta, em grande propcrção, inúmeras modificações resultantes da depreciação do ativo assim calculado".

Nesta ordem de idéias, observou o Sr. IlEGEMS, é mister que a dotação para a amortização da dívida pública atinja, pelo menos, $a$ valor do encargo de amortização dos bens do Estado. Para isso, também, é indispensável um conhecimento profundo do valor dos bens capitais do Estado.

Até a hora atual, os dados relativcs ao valor e à constituição dos bens do Estado são fornecidos, mediante inventário dêsses bens, elaborado periò- 
dicamente, desde 1932, pela Comissão permanente incumbida da atualização regular do cadastro geral dos bens do Estado. Desde 1932, porém, essa Comissão tem insistido no caráter precário do seu trabalho.

"Não se trata apenas de elaborar uma vez, à custa de trabalho difícil, inventário mais ou menos completo dos bens do Estado. Nem mesnio bastará fechar êsse inventário em determinados prazos. O que é preciso é mantê-lo permanentemente em dia. A nosso ver, será necessário, depois de elaborado uma vez o balanço geral do Estado, que o mesmo seja mantido atualizado de ano para ano. Ao ativo se acrescentará a contrapartida de tôdas as despesas feitas durante o exercício e que poderá ser considerada como aumentando efetivamente o acêrvo do Estado. Ao passivo se incluirão as modificações, para mais e para menos, verificadas da dívida pública. Certas ccntas de amortização serão apresentadas e o mecanismo das mesmas deverá ser objeto de acurado estudo posterior."

Depcis de evocar as realizações de outros países em matéria de contaLilidade patrimonial (Suiça, Holanda, Congo Belga) observou o Sr. Ilegems que a adoção de tal contabilidade na Bélgica não ofereceria grandes dificuldades.

Os dados atualmente coligidos pela contabilidade pública, bem como os valiosos trabalhos da Comissão permanente incur.bida da atualização regular do cadastro geral dos bens do Estado, já desbravaram grandemente o terreno nesse particular. Seria mister, entretanto, distinguir melhor as despesas correntes das despesas de capital, introduzir na contabilidade pública ccritas para credores e devedores, etc.

A exposição do Sr. Ilegems foi completada por uma ccmissão do $\mathrm{Sr}$. G. VERREIST, Inspetor Real das Colônias, relativamente à "Situação patrimo. nial do Congo Belga a 31 de dezembro de 1949". (1)

Já en: fins de 1947, havia sido levantada a questão de modificar-se a apresentação da contabilidade pública do Ccngo Belga e adotar-se a forma de contabilidade patrimoniel.

A elaboração do Plano Decenal contribuiu para aumentar ainda mais o interêsse em tôrno da questão. No momento em que a Colônia se dispunha a empreender vastas obras de investimento, importante se tornava justificar o bum emprêgo dos créditos concedidos, salientando o aumento de patrimônio, que resultava dêles.

Tratava-se, pois, de elaborar um balanço, no qual se acrescentariam, anualmente, os investimentos realizados.

Dois métcodos permitiram a adoção do plano inicial:

A. O método contábil, que consiste em transcrever nas contas gerais tôdas as despesas de investimento realizadas desde a origem da Colônia, atri-

(1) Êsse relatório foi publicado na íntegra no Bulletin de la Banque Centrale du Congo Belge et du Ruanda-Urandi, Ano I, n. ${ }^{\circ}$ 3, setembro de 1952. 
buindo-lhes, de um lado, um coeficiente de amcrtização segundo a natureza e a data das obras projetadas e, de outro, acrescentando-lhes uma taxa de revalorização, segundo a depreciação da moeda;

B. O método de estimativa direta, que comporta a avaliação dos bens da Coliônia, em função do respectivo custo de substituição atual levando-se em conta o desgaste ou a vetustez.

O método contábil, em princípio muito simples, foi adotado inicialmente. Os trabalhos de compilação das contas gerais foram iniciados durante o ano de 1949.

A 31 de dezembro de 1948, foi encerrado um primeiro balanço elaborado por essa forma. O resultado final, calculando em oito bilhões o valor do patrimônio da Colônia, pareceu excessivamente m.odesto.

Com o recurso de dados provenientes de outras fontes, o balanço seguinte, encerrado em 31 de dezembro de 1949, foi elaborado pelo método de estirnativa direta, mitigado, até certo ponto, pelo emprêgo de valcres arbitrárics e pela manutenção, em certos casos precisos, do método contábil.

Tal como elaborado, o balanço encerrado em 31 de dezembro de 1949 servirá de base para o confronto dos investimentos dos anos seguintes, cujos elementcs serão tirados das contas. Periòdicamente, de dez em dez anos, por exemplo, nova estimativa direta do patrimônio da Colônia permitirá o reajustamento dos resultados obtidos pelo método contábil.

Paralelamente a êsses trabalhos de estudo, realizou-se importante reforma no Congo Belga relativamente à execução do serviço da fazenda e ac emprêgo de métodos mecanográficos para a centralização das operações contábeis. Aplicada progressivar.ente ao cálculo e à liquidação dos emolumentos, depcis estendida à contabilidade do Ruanda-Urundi a título experimental, deu bom resultado e está generalizada às operações do Congo Belga desde $10^{\circ}$ de janeiro de 1952 .

Graças ao emprêgo das máquinas de perfuração de fichas, a divisão ou a seleção de certas despesas torna-se extremamente fácil. Uma modificação mínima do dispositivo atual dos orçamentos permitiria ir buscar automàticamente na contabilidade pública os elementos necessários à manutenção do balanço patrimonial. Bastaria para tanto que, numa mesna subdivisão orçamentária (consignação ou subconsignação de verba) não mais se preveja um crédito para cobrir ao mesmo tempo despesas correntes e despesas de investimento. Quer incluídas como despesas ordinárias ou extraordinárias, as despesas de investimento seriam, destarte, extraídas das contas gerais $\mathrm{ccm}$ a garantia absoluta de que nenhum item pode escapar às investigações.

O Sr. Buttgenbach, Professor da Universidade de Liège, fôra convidado a examinar os "Problemas de terminologia e de classificação" que resultan: das discordâncias existentes entre as noções clássicas do Estado, de administrações subordinadas, de órgãos paraestatais, etc., e o sentido que a contabilidade nacional atribui a êsses têrmos. 
Relativamente ao setor "Particulares" e "Restos do mundo", o conferencista manifestou-se favorável à terminologia atualmente preconizada pela O.E.C.E. No tocante ao setor "emprêsas" e "Estado", sugeriu as seguintes denominações:

O setor "Emprêsas" seria subdividido em dois subsetores: "Emprêsas privadas" e "Emprêsas públicas". A fim de melhor salientar o caráter próprio de cada um dêsses dois subsetores, o primeiro compreenderia o subtítulo "Pessoas físicas e órgãos privados" o segundo, "Poderes e órgãos públicos".

O Sr. ButTGENBaCH propôs igualmente substituir-se o têrmo "Estado" por "Setor público adrrinistrativo e social", com o subtítulo de "Poderes e urganismos públicos".

Opondo-se o setor público "administrativo e social" ao setor público "emprêsas", fica suficientemente esclarecida a intenção de não incluir no mesmo senão as atividades dos poderes e organismos públicos que não representem atividiades de emprêsa.

Êsse setor compreenderá também, normalmente, as operações dos serviços governarr-entais que, na terminalogia corrente, são compreendidas nas receitas e despesas de "administração".

Esclarecendo tratar-se do setor "público", diferencia-se o mesnco do setor "particulares".

Acrescentando-se - tal como para o setor "emprêsas públicas" que se trata das operações dos "poderes e órgãos públicos", fica, finalmente, esclarecido cogitar-se do Estado, das províncias, das comunas e de todos os órgãos pelos mesmos criados, qualquer que seja a respectiva forma e qualquer que seia o seu estatuto político.

A comunicação do Sr. Magain, Chefe de Gabinete do Primeiro Ministro teve por tema "A Adaptação - tendo em vista sua integração na contabilidade nacional - do orçamento dos órgãos de interêsse público dotados de autonomia orgânica ou de certa autonomia técnica".

O conferencista insistiu no fato de que, tendo em vista as exigências da contabilidade nacional, o problema a ser resclvido é duplo:

— os orçamentos dos serviços que desempenhem missão administrativa ou social devem concordar com o esquema da conta "Estado" da Contabilidade Nacional;

- 0 orçamento dos serviços que desempenham missão industrial, comercial ou financeira deve ser calcado sôbre o da conta " $\mathrm{Em}$ prêsas" da Contabilidade Nacional.

Em outras palavras, trata-se de elaborar duas espécies de esquema:

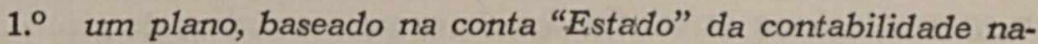
cional, do orçamento dos órgãos de interêsse público autônomos, de caráter administrativo e social; 
2. - um plano baseado na conta "Emprêsas" da contabilidade nacional, dos órgãos de interêsses público, autônomos (até mesmo de certas administrações não perscnalizadas), de caráter industrial, comercial ou financeiro.

O esquema, relativamente aos órgãos da primeira categoria, corresponde, em linhas gerais, ao plano do orçamento dos serviços do Estado apresentado pelo Sr. FranK e reproduzido no Quadro I.

Quanto ao esquema dos órgãos da segunda categoria, êste pode ser apresentado consoante duas variações:

- a adotada pela O.E.C.E., compreendendo três contas: conta de produção, conta de aplicação e ccnta das operações de capital;

- a adotada pela BEDRIJVENWET holandesa de 21 de julho de 1928, compreendendo apenas duas contas, em virtude do grupamento das operações da conta de produção e da conta de aplicação numa só conta das cperações correntes.

Os dois sistemas acima esboçados têm suas vantagens e desvantagens respectivas. O da O.E.C.E. satisfará antes os que se preocupam em fazer corresponder tanto quanto possível, a contabilidade das emprêsas públicas à đas emprêsas privadas; chocará, em compensação, as concepções dos meios parlamentares habituados à subdivisão das receitas e despesas públicas em orçamento ordinário e orçamento extraordinário.

O sistema da BEDRIJVENWET holandesa deve, pelas mesmas razões, obter os sufrágios dos partidários da contabilidade pública tradicional mas, em compensação, encontrará oposição por parte dos adeptos dos métodos da ccntabilidade privada.

- Segundo o Sr. MagaIn, é muito difícil optar-se, de modo absoluto, em favor de um dos dois sistemas em exame. A concepção do O.E.C.E. parece adaptar-se antes às emprêsas públicas não subordinadas à autoridade de ur. ministro e cujo orçamento não é sujeito à aprovação do Parlamento. A concepção da BEDRIJVENWET parece, em compensação, mais de acôrdo com as exigências das emprêsas públicas subordinadas à autoridade ministerial e cujo orçamento é votado pelo Parlamento.

O conferencista examinou, por fim, os dispositivos do projeto de lei relativo ao contrôle de certos órgãcs de interêsse público, apresentado em 25 de março de 1952 à mesa da Câmara dos Representantes.

O projeto em questão prevề que certo número de "régies" e estabelecinıentos públicos, entre os mais importantes que existem na Bélgica, serian: doravante obrigados a elaborar um crçamento de acôrdo com certas regras e apresentação, a serem fixadas de comum acôrdo pelo ministro ao qual são êsses órgãos subordinados e pelo Ministro das Finanças. Êsses orçamentos seriam anexados ao projeto do orçamento do ministério a que foram subordi- 
nados os órgãos e subrretidos às casas legislativas para aprovaçãc, ou então comunicados às mesnıas a título de informação.

A incumbência de fixar as regras gerais e particulares relativas à apresentação dos orçamentos, nos têrmos do projeto de lei, caberia ao Poder Executivo. Este teria assim oportunidade bem propícia para basear na contabilidade nacional o plano do orçamento dos órgãos de interêsse público.

O único dispcsitivo taxativo contido no projeto é o que estipula que "a contabilidade é mantida de ácôrdo com o sistema da gestão". Êsse dispositivo, longe de constituir obstáculo à reforma projetada, facilitaria, pelo contrário, sua realização.

$\mathrm{Na}$ previsão da votação do projeto de lei relativo ao contrôle de certos órgãos de interêsse público, o Ministro das Finanças convocou alguns dos mesmos a apresentarem, a partir do exercício de 1952, um orçamento de acôrdo com regras e apresentação correspondendo, sob inúmeros aspectos, aos esciueras acima referidos.

O Sr. Chatel, funcionário da Administração do Tesouro, tratou do prablema da "Previsão da conta do Tesouro do Estado".

O conferencista externou sérias reservas quanto à possibilidade de elaburar tal previsão.

As contas "extra-orçamentárias" provocam, de fato, manipulações de fundos e transferências de créditos, de amplitude bem mais consideráveis que a simples execução crçamentária.

Se, por um lado, a importância das receitas e despesas orçamentárias pade ser determinada com bastante facilidade, por isso que a execução do orçamento é "comandada", o mesmo não acontece con. os movimentos do Tescuro, que são "impostos" e dependem muito mais da evolução da conjuntura, que da iniciativa governamental.

Finalmente, as receitas e despesas orçamentárias têm, no Tesouro, importância bem menos considerável do que pareceria pela magnitude das cifras que aparecem nos orçamentos.

As operações orçamentárias, com exceção de parcelas muito sérias. não têm outros efeitos além dos de simples transferência na conta e, isto mesmo, em ccnseqüência do sistema de vasos comunicantes existentes entre o Tesouro, o Banco Nacional, o Escritório de Cheques Postais e os bancos privados. Todos êsses ór gãos financeiros constituem apenas um único e mesmo circuito fechado.

O Sr. Chatel insistiu longamente, apoiado em cifras, neste último ponto.

A contabilidade do Tesouro é uma contabilidade bancária, mas de banco que nada possui de seu. A conta do orçamento, nas escritas do Tescuro, é uma conta! corrente entre muitas outras. Nessas contas, encaixa-se boa parcela da poupança pública.

As previsões de tesouraria, já difíceis de estabelecer nos bancos privados - onde são feitas apenas a curto prazo ¿ durante breve período e onde as operaçōes não têm a amplitude que assumem no Estado, são muito mais difíceis 
relativamente ao Tesouro, principalmente quando se trata de elaborá-las muito antes do vencimento e por período prolongado. Essas previsões são tanto mais difíceis de determinar, quanto o Tesouro não é forçado à disciplina bancária do paralelismo dos compromissos. O que recebe em depósito de um de seus correspcndentes, o Tesouro toma, não raro, a liberdade de gastá-lo em proveito de outro.

O Sr. V. DE RIDDER, finalmente, ventilou um problema essencial e, ao mesmo tempo, explosivo - $A$ Contabilidade nacional, instrumento de análise estatística ou de política econômica?

Em sua exposição, procurcu o autor demonstrar que a contabilidade nacicnal, como simples técnica estatística e método objetivo de recenseamento e classificação do conjunto das atividades econômicas de um país, nada tem que ver com $a$ binômio dirigismo-liberalismo.

O objetivo dêsse método científico de investigação econômica é ùnicamente conhecer e compreender melhor, mercê de apresentação sistemática e adequada, a estrutura, o funcionamento e os resultados da atividade eca nômica.

Poder-se-ia, em seguida, deduzir dos elementos objetivos de conhecimento e apreciação assim reunidos, conclusões que seriam aplicadas na busca de uma política econômica determinada. Trata-se, porém, de decisões da alçada exclusiva dos governos e com as quais nada tem que ver o especialista em contabilidade nacional, como tal; seu papel consiste ùnicamente em aperfeiçoar o instrumento técnico de estudo e trabalho. Cabe, então, aos políticos, resolver para que fim e em que sentido será aproveitado êsse instrumento.

A utilidade da contabilidade nacional como inventário estatístico é evidente e apresenta múltiplos aspectos; resulta da própria definição dessa nova técnica. A visão global e sisterrática da economia nacional que a mesma proporciona apresenta várias vantagens, do ponto de vista da economia quer teórica, quer prática.

A natureza \& a amplitude das repercussões que êste ou aquêle fator determinado provoca para os diversos setores e transações econômicas permitem fazer-se uma idéia bem mais precisa dos mecanismos complexos e dos laços de causalidade que se encontram na base do funcionamento de economia. $\hat{E}$, aliás, êsse objetivo fundamental que deu origem aos primeiros trabalhos macro-econômicos, notadamente quando se tratou, durante a década de 1930 , de revelar as causas da depressão e medir a importância quantitativa das reaçóes observadas.

Do ponto de vista da terminologia, igualmente, as necessidades de mensuração e classificação estatística contribuiram para precisar ainda mais os diversos conceitos macro-econômicos, de modo que a teoria econômica pode assim trabalhar com definições mais rigorosas e homogêneas.

A estatística eccnômica, por seu lado, aproveitou grandemente o desenvolvimento da contabilidade nacional, por isso que êsse novo métcdo permitiu reunir num conjunto coerente e funcional a multidão das estatísticas econômicas esparsas. Pode-se, pois, coordenar, em função do objetivo comum, 
os elementos estatísticos disponíveis ou por reunir, enquanto que as principaiis. lacunas ou deficiências estatísticas ainda existentes em certos setores são igualmente reveladas.

Mencionemos ainda vários setores da eccnomia aplicada para os quais. os dados da contabilidade nacional são, igualmente, da grande utilidade. E' o que acontece, especialmente, no tocante às pesquisas econométricas, a análise dos mercados e certos aspectos da econcmia interna das emprêsas.

Finalmente, não há dúvida que do ponto de vista didático, também, o bosquejo sistemático e coerente que a contabilidade nacional proporciona acêrca da eccnomia, muito facilita o ensino econômico; a visualização e a concretização dos vários mecanismos econômicos pernitem melhor explicar e melhor compreender os complexos laços que unem todos os fatôries da economia. Por isso mesmc, não é de admirar que desde que a contabilidade nacional conquistou definitivamente o direito de existir os países mais adiantados no terreno da análise macro-econômica, notadamente os Estados Unidos, a Grã-Bretanha e a Holanda, tenham introduzido nos programas de suas universidades, cursos para o estudo da potência macro-econômica e que êsse ensino faça hoje parte da formação dos novos eccnomistas.

As mesmas razões que explicam a utilidade da contabilidade nacional para o estudo econômico teórico e prático militam também em favor de emprêgo dessa técnica como base ou auxiliar da política econômica.

Em qualquer que seja o regime, mesmo num completo "laisserfaire", existirá sempre em ação alguma política econômica visando precisamente à realização dos objetivos fixados pelo regime. Êsses objetivos só podem ser atingidos mediante aertos meios de ação. A contabilidade nacional, pelo conjunto dos dados e conhecimentos concretos que proporciona sôbre a estrutura, o funcioisamento e os resultados da atividade econômica, permite, precisamente, fixar, com conhecimento de causa, os objetivos a atingir e os meios mais adequados a serem usados para êsse fim. Ao mesmo tempo, as indicações deduzidas da experiência passada traçarão os limites e condições impostos à ação. dos poderes públicos num ou noutro sentido ou terreno de determinado setor.

Graças aos laços orgânicos e às relações quantitativas que as contas não permitem estabelecer entre cs diversos componentes da economia, torna-se possível determinar cientificamente, não sömente a natureza, como também. a amplitude das medidas a serem tomadas para provocar repercussões desejadas.

Os relatórios submetidos à Jornada de Estudos de 6 de dezembro de 1952 e as discussões realizadas durante a mesma, mostram a utilidade que representaria uma revisão da apresentação dos orçamentos e da conta da Tesouraria, com o fim de baseá-los na contabilidade nacional. As reformas propostas suscitam, evidentemente, inúmercs problemas técnicos.

O Instituto Belga de Finança Pública foi, portanto, bem inspirado ao criar, em seu seio, uma Comissão de estudos para a integração da contabilidade pública na contabilidade nacional. Essa comissão presidida pelo Prof. MASorn, está incumbida de analisar os trabalhos da Jcrnada de estudos e apresentar ao Govêrno recomendações visando à concretização da reforma. 